\title{
Sleeve Gastrektomi Uygulanan Hastalarda Ağırlık Kaybının Nonalkolik Yağlı Karaciğer ile İlgili Bazı Yeni Parametreler Üzerine Etkisi
}

\author{
The Effect of Weight Loss on Novel Parameters of Nonalcoholic Fatty Liver Disease Undergoing \\ Sleeve Gastrectomy
}

\author{
Evrim Kahramanoğlu Aksoy', Zeynep Göktaş ${ }^{2}$ Özgür Albuz ${ }^{3}$, Muhammet Yener Akpınar ${ }^{4}$, Doğan Öztürk \\ Hakan Buluş ${ }^{6}$, Metin Uzman ${ }^{7}$
}

Geliş tarihi/Received: 30.10.2018 • Kabul tarihi/Accepted: 30.11.2018

\section{ÖZET}

Amaç: Morbid obez hastalarda bariatrik cerrahinin nonalkolik yağlı karaciğer hastalığı (NAYKH)'nın hem histolojik hem de karaciğer enzimleri üzerine olumlu etkisi olduğu bilinmektedir. Bu çalışmanın amacı sleeve gastrektominin morbid obez hastalarda NAYKH ile ilgili bazı parametreler üzerine etkilerini incelemektir.

Bireyler ve Yöntem: Ocak 2017-Ocak 2018 tarihleri arasında sleeve gastrektomi ameliyatı yapılan 70 hasta çalışmaya dahil edilmiştir. Ameliyat öncesi ve ameliyatın 12. ayındaki laboratuvar parametreleri ve antropometrik ölçümleri hasta dosya arşivinden kaydedilmiştir. Hastaların beden kütle indeksi (BKİ), gamaglutamiltransferaz-platelet oranı (GPR), mutlak nötrofil sayısı/mutlak lenfosit sayısı (NLR), mutlak platelet sayısı/mutlak lenfosit sayısı (PLR), mutlak monosit sayısının yüksek dansiteli lipoprotein (HDL)'e oranı (MHR), HOMA-IR, karaciğer enzimleri, toplam ağırlık kaybı (TWL) ve aşırı ağırlık kaybı (EWL) hesaplanmıştır.

Bulgular: Hastaların BKİ, HOMA-IR, karaciğer enzimleri, GPR, NLR, MHR değerlerinde 12. ayda anlamlı düşüş izlenirken, PLR değeri açısından fark saptanmamıştır. TWL, EWL ve NAYKH parametreleri arasında korelasyon belirlenmemiştir.

Sonuç: Sleeve gastrektomi ameliyatı olmuş NAYKH hastalarının izleminde takibinde GPR, MHR, NLR kullanılabilecek basit parametrelerdir.

Anahtar kelimeler: Sleeve gastrektomi, obezite, nonalkolik yağll karaciğer hastalı̆̆l (NAYKH)

\section{ABSTRACT}

Aim: In morbid obese patients bariatric surgeries seem to have positive effects on nonalcoholic fatty liver disease (NAFLD) both histologically and enzymatically. Purpose of this study was to evaluate the effects of sleeve gastrectomy on NAFLD related parameters in morbid obese patients.

1. İletişim/Correspondence: Sağlık Bilimleri Üniversitesi, Keçiören Eğitim ve Araștırma Hastanesi, Gastroenteroloji Kliniği, Ankara, Türkiye

E-posta: evrims1979@yahoo.com• • ㄴ https://orcid.org/0000-0001-8887-3428

2. Hacettepe Üniversitesi, Sağlık Bilimleri Fakültesi, Beslenme ve Diyetetik Bölümü, Ankara, Türkiye

(1) https://orcid.org/0000-0001-7241-8017

3. Sağllk Bilimleri Üniversitesi, Keçiören Eğitim ve Araştırma Hastanesi, Genel Cerrahi Kliniği, Ankara, Türkiye

(1) https://orcid.org/0000-0002-8534-1781
4. Hacettepe Üniversitesi, Sağlık Bilimleri Fakültesi, Beslenme ve Diyetetik Bölümü, Ankara, Türkiye • — $\odot$ https://orcid.org/0000-0003-0903-4664

5. Sağllk Bilimleri Üniversitesi, Keçiören Eğitim ve Araştırma Hastanesi, Genel Cerrahi Kliniği, Ankara, Türkiye • • ㄴ https://orcid.org/0000-0003-1754-9246

6. Sağllk Bilimleri Üniversitesi, Keçiören Eğitim ve Araştırma Hastanesi, Genel Cerrahi Kliniği, Ankara, Türkiye • ๑ https://orcid.org/0000-0003-2555-4707

7. Sağılı Bilimleri Üniversitesi, Keçiören Eğitim ve Araștırma Hastanesi, Gastroenteroloji Kliniği, Ankara, Türkiye 으 https://orcid.org/0000-0002-5412-8523 
Subjects and Method: A total of 70 patients who underwent sleeve gastrectomy surgery, were included in the study. Laboratory parameters and anthropometric measurements before and 12 months after the surgery were recorded from the hospital records. Body mass index (BMI), gamma-glutamyl transpeptidase-to-platelet ratio (GPR), neutrophil to lymphocyte ratio (NLR), platelet to lymphocyte ratio (PLR), monocyte count to high-density lipoprotein (HDL) cholesterol ratio (MHR), HOMAIR, liver enzymes, total weight loss (TWL), and excess weight loss (EWL) of patients were calculated.

Results: While there were significant decrease in BMI, HOMA-IR, liver enzymes, GPR, NLR, and MHR levels at the 12th month, PLR levels did not show any difference. There were no correlations between TWL, EWL and NAFLD parameters.

Conclusion: GPR, MHR, NLR are the simple parameters that can be used in the follow-up of NAFLD patients who underwent sleeve gastrectomy.

Keywords: Sleeve gastrectomy, obesity, nonalcoholic fatty liver disease (NAFLD)

\section{GíRIŞ}

Beden kütle indeksi (BKİ)’nin >30 kg/m² olması obezite olarak tanımlanır. Dünya Sağlık Örgütü’nün 2014 yılı verilerine göre tüm dünyada 1.9 milyar insanın kilolu, 600 milyon insanın obez olduğu bilinmektedir (1). Obezite, kardiyovasküler hastalıklar, solunum sistemi hastalıkları, sindirim sistemi hastalıkları ve serebrovasküler hastalıklara yol açmanın yanı sıra hipertansiyon, dislipidemi, hiperinsülinemi, insülin direnci (ID), tip 2 diabetes mellitus (DM), non-alkolik yağlı karaciğer hastalığı (NAYKH) ve metabolik sendrom ile de ilişkili yaygın bir halk sağlı̆̆ı sorunu, önemli bir mortalite ve morbidite nedenidir (2). BKİ $\geq 40 \mathrm{~kg} / \mathrm{m}^{2}$ veya $\geq 35 \mathrm{~kg} / \mathrm{m}^{2}$ olup obezite ilişkili komorbidetesi olan ve yeterli sürede tıbbi tedavi ve diyete yanıt vermeyen hastalar bariatrik cerrahiye adaydirlar (3).

NAYKH,karaciğerdetrigliseritşeklindeaşırıyağbirikimi sonucu oluşur. Yağlanmanın yanı sıra karaciğer hücre hasarı ve inflamasyonun olduğu durum ise nonalkolik steatohepatit (NASH) olarak tanımlanır. NAYKH, basit yağlanmadan siroza hatta hepatoselüler kansere kadar ilerleyen hastallk spektrumunu kapsar (4). Obezlerin \%80'inde NAYKH, \%15-56'sında NASH ve \%2-4'ünde siroza rastlanmaktadır (5). Obezitede İD’ye yol açan inflamasyon NAYKH patogenezindeki en önemli etkendir (6). Hem NAYKH hem de NASH hastalarında bariatrik cerrahinin hem karaciğer histopatolojisine hem de karaciğer fonksiyon testlerinde düzelmeye katkısı olduğu bildirilmiştir $(7,8)$.
Randellve arkadaşları (9), sleeve gastrektomi ameliyatı yapılan ciddi obez hastalarda alanin aminotransferaz (ALT) ve gamaglutamiltransferazın (GGT) yanı sıra C-reaktif protein (CRP) ve ferritin gibi akut faz reaktanlarında da anlamlı düşüşü göstermişler ve ALT ve CRP arasında negatif korelasyon saptamışlardır.

NAYKH tanısında altın standart yöntem karaciğer biyopsisidir. Ancak hem invaziv bir yöntem oluşu hem de pahalı olması klinisyenleri hastaların izlemi için kolay ulaşılabilir, noninvaziv laboratuvar kaynaklı parametreler kullanmaya yöneltmektedir (10). GGTplatelet oranı (GPR) NAYKH'da son yıllarda fibrozis derecesini saptamak için kullanılmaya başlanan bir parametredir (11).

Daha önceki çalışmalarda nötrofil-lenfosit oranı (NLR), platelet-lenfosit oranı (PLR) ve monosit-yüksek dansiteli lipoprotein (HDL) oranının (MHR) metabolik sendromun belirlenmesinde kullanılabilecek inflamatuvar belirteçler olduğu gösterilmiştir (12-15).

Mevcut bilgilerimize göre bariatrik cerrahi yapılan hastalarda bu oranlarla yapılan çalışma bulunmamaktadır. $\mathrm{Bu}$ çalışmanın amacı sleeve gastrektomiyapılan morbid obez hastalarda operasyon öncesi ve operasyonun birinci yllındaki laboratuvar parametrelerini, antropometrik ölçümlerini, NLR, PLR, MHR ve GPR oranlarını saptamak ve birbirleri ile olan ilişkilerini değerlendirmektir. 


\section{BIREYLER VE YÖNTEM}

\section{Hastalar ve Veri Toplanması}

Keçiören Eğitim ve Araştırma Hastanesi Genel Cerrahi Kliniği'nde sleeve gastrektomi ameliyatı yapılan, çalışma öncesi NAYKH saptanan 70 hasta çalışmaya dahil edilmiştir. 18 yaş altı ve 65 yaş üstü hastalar, kronik inflamatuvar hastalığı olan hastalar, tiroid hastaları, kronik böbrek hastalığı olan, aktif enfeksiyonu olan hastalar, hepatit B ve hepatit C virüs saptanan hastalar, antikoagülan, antitrombosit ilaç kullanan hastalar ve izleme gelmeyen hastalar çalışma dışı bırakılmıştır. Oral antidiyabetik kullanan Diabetes Mellitus (DM) ve antihipertansif kullanan hipertansiyon hastaları çalışmaya dahil edilmiştir. Sleeve gastrektomi ameliyatı sonrası, oral antidiyabetik kullanan hastaların 9 tanesinde ilaç gereksinimi kalmazken, 6 tanesinde kullanılan doz miktarı azalmış, 4 tanesinde aynı doz ilaç kullanımı devam etmiştir. Antihipertansif kullanan hastaların 4 tanesi ilaç kullanmayı bırakmış, 7 tanesi aynı dozda devam etmiştir.

Sleeve gastrektomi, obezite cerrahisinde son yllarda artan oranda kullanılmakta ve "tüp mide" olarak da adlandırılmaktadır. Antrumdan başlanarak proksimalde his açısına kadar olan büyük kurvatur rezeke edilir. Mide hacmi azalır ve sonuçta alınan besin miktarı düşer. Ameliyat sonrası emilimde sorun olmadığı için vitamin ve mineral desteği gerekmez. Ayrıca açlık hormonu olarak bilinen ve fundustan salınan ghrelin hormon miktarında da azalma olur.

Hasta dosyalarmdan restrospektif olarak ameliyat sırasında ve ameliyatın 1. yllındaki laboratuvar parametreleri ve antropometrik ölçümleri kaydedilmiştir. Aşağıdaki hesaplamalar yapılmıştır.

- $\quad$ NLR=Mutlak nötrofil sayısı/mutlak lenfosit sayısı

- PLR=Mutlak platelet sayısı/mutlak lenfosit sayısı

- $\mathrm{MHR}=$ Mutlak monosit sayısı/HDL oranı

- $\mathrm{GPR}=\mathrm{GGT} /$ normalin üst sinırı /mutlak platelet sayısı $\left(10^{9} /\right.$ litre $) \times 100$

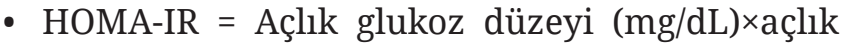
insülin düzeyi $(\mu \mathrm{U} / \mathrm{mL}) / 405$

- Toplam ağırlık kaybı \% (\%TWL)= (başlangıç ağırlığı-şimdiki ağırlık)/başlangıç ağırlığı×100

- Aşırı ağırlık kaybı \% (\%EWL)= (başlangıç ağırlığışimdiki ağırlık)/(başlangıç ağırlığı-ideal ağırlık) $\times 100(16)$

Hastaların laboratuvar ölçümleri en az 12 saat açlık sonrası alınan ve 2 saat içerisinde laboratuvara ulaşan venöz kan örneklerinden yapılmıştır. Kan örnekleri 5000 bpm/dakika'da en az 10 dakika santrifüj edilmiştir. Hemogram, CRP, albümin, kreatinin, ALT, aspartat aminotransferaz (AST), GGT, alkalen fosfataz (ALP), total bilurubin, glukoz, HDL, trigliderid (TG), total kolesterol, insülin, hemoglobin A1C (HbA1C) değerleri kaydedilmiştir.

$\mathrm{Bu}$ çalışma Sağlık Bilimleri Üniversitesi, Keçiören Eğitim ve Araştırma Hastanesi Etik Kurulu tarafından etik açıdan uygun bulunmuştur (9.06.2017 tarihli ve 43278876-929-442-3138 sayılı) Tüm katılımcılara çalışma konusunda bilgi verildikten sonra onam formu imzalatılmıştır.

\section{Verilerin İstatistiksel Değerlendirmesi}

Veriler SPSS IBM 22.0 programı kullanılarak analiz edilmiştir. Sayısal veriler ortalama \pm standart sapma $(\bar{X} \pm S)$ olarak belirtilmiştir. Nominal veriler sayı (n) ve yüzde (\%) olarak belirtilmiştir. Sayısal veriler dağılım normalitesi incelenerek iki grup arası ortalamaların değerlendirilmesinde eşleştirilmiş t test kullanılmıştır. Parametreler arasındaki ilişkiler Pearson Korelasyon katsayısı kullanılarak değerlendirilmiştir. p değeri 0.05'in altında istatistiksel olarak anlamlı sayılmıştır.

\section{BULGULAR}

Hastaların ortalama yaşı $38.0 \pm 11.76$ yıl, ortalama vücut ağırlığı 123.7×15.92 kg, \%72.9’u erkek, \%27.1’i kadındır. Toplam 11 hastada hipertansiyon, 19 hastada tip 2 DM, 7 hastada dislipidemi saptanmıştır (Tablo 1). 
Tablo 1. Hastaların temel demografik özellikleri ( $\mathrm{n}=70)$

\begin{tabular}{ll}
\hline Özellikler & \\
\hline Yaş (yıl) $\left(\overline{\mathrm{X}}_{ \pm S}\right)$ & $38.0 \pm 11.76$ \\
Ağırlık $(\mathrm{kg})\left(\overline{\mathrm{X}}_{ \pm} \mathrm{S}\right)$ & $123.7 \pm 15.92$ \\
Cinsiyet \% (erkek/kadın) & $72.9 / 27.1$ \\
Hipertansiyon (\%) & $11(\% 15.7)$ \\
Diabetes mellitus (\%) & $19(\% 27.1)$ \\
Dislipidemi & $7(\% 15.7)$ \\
\hline
\end{tabular}

Hastaların cerrahi öncesi ve cerrahinin 1. yılındaki verileri karşılaştırıldığında ağırlık, BKİ, HbA1C \%, glukoz, insülin, HOMA-IR, HDL, TG, lökosit, nötrofil, monosit, platelet, ferritin, değerlerinde istatistiksel olarak anlamlı düşüş, D vitamini ve albümin değerlerinde istatistiksel olarak anlamlı yükselme saptanmıştır (Tablo 2).

Tablo 2. Hastaların ameliyat öncesi ve ameliyat sonrası 12. aydaki antropometrik ölçümleri ve biyokimyasal parametreleri $(\mathrm{n}=70)$

\begin{tabular}{|c|c|c|c|c|}
\hline \multirow{2}{*}{$\begin{array}{l}\text { Antropometrik ölçümler ve } \\
\text { biyokimyasal parametreler }\end{array}$} & Ameliyat öncesi & $\begin{array}{c}\text { Ameliyat sonrası } \\
\text { (12. ay) }\end{array}$ & $\begin{array}{l}\text { Eşleştirilmiş } \\
\text { farklılıklar }\end{array}$ & \multirow{2}{*}{$\mathbf{p}$} \\
\hline & $(\overline{\mathrm{X}} \pm \mathrm{S})$ & $(\overline{\mathrm{X}} \pm \mathrm{S})$ & $(\overline{\mathrm{X}} \pm \mathrm{S})$ & \\
\hline Ağırlık (kg) & $123.7 \pm 15.92$ & $76.9 \pm 9.55$ & $46.7 \pm 11.53$ & $<0.001$ \\
\hline BKİ $\left(\mathrm{kg} / \mathrm{m}^{2}\right)$ & $44.9 \pm 5.22$ & $27.6 \pm 3.59$ & $17.4 \pm 4.91$ & $<0.001$ \\
\hline HbA1C (\%) & $6.23 \pm 1.15$ & $5.21 \pm 0.77$ & $1.01 \pm 0.81$ & $<0.001$ \\
\hline Glukoz (mg/dL) & $109.1 \pm 39.41$ & $84.5 \pm 9.93$ & $24.6 \pm 34.91$ & $<0.001$ \\
\hline İnsülin (mg/dL) & $14.8 \pm 5.86$ & $6.06 \pm 2.56$ & $8.72 \pm 5.29$ & $<0.001$ \\
\hline HOMA-IR & $4.09 \pm 2.43$ & $1.31 \pm 0.54$ & $2.77 \pm 2.17$ & $<0.001$ \\
\hline Kreatinin (mg/dL) & $0.72 \pm 0.10$ & $0.72 \pm 0.11$ & $0.01 \pm 0.11$ & $>0.05$ \\
\hline Total protein (g/dL) & $7.78 \pm 1.33$ & $6.93 \pm 0.19$ & $0.85 \pm 1.21$ & $>0.05$ \\
\hline Albümin (g/dL) & $3.93 \pm 0.34$ & $4.30 \pm 0.22$ & $-0.37 \pm 0.41$ & 0.001 \\
\hline Total bilurubin (mg/dL) & $0.75 \pm 0.55$ & $0.85 \pm 0.63$ & $-0.09 \pm 0.53$ & $>0.05$ \\
\hline Direk bilirubin (mg/dL) & $0.28 \pm 0.23$ & $0.28 \pm 0.13$ & $0.004 \pm 0.22$ & $>0.05$ \\
\hline Total kolesterol (mg/dL) & $213.7 \pm 33.38$ & $200.1 \pm 25.22$ & $13.6 \pm 35.67$ & $>0.05$ \\
\hline HDL (mg/dL) & $38.4 \pm 5.70$ & $47.5 \pm 8.20$ & $-9.06 \pm 7.09$ & $<0.001$ \\
\hline Trigliserit (mg/dL) & $197.4 \pm 78.15$ & $122.0 \pm 80.31$ & $75.4 \pm 64.65$ & 0.001 \\
\hline Lökosit (×103/L) & $8.62 \pm 2.09$ & $7.19 \pm 1.71$ & $1.43 \pm 2.36$ & 0.004 \\
\hline Neutrofil (×103/L) & $5.39 \pm 1.81$ & $4.16 \pm 1.30$ & $1.24 \pm 1.82$ & $<0.001$ \\
\hline Lenfosit (×103/L) & $2.59 \pm 0.79$ & $2.49 \pm 0.69$ & $0.11 \pm 0.44$ & $>0.05$ \\
\hline Monosit (×103/L) & $0.57 \pm 0.14$ & $0.42 \pm 0.11$ & $0.15 \pm 0.16$ & $<0.001$ \\
\hline Platelet (×103/L) & $271.2 \pm 74.26$ & $295.5 \pm 73.59$ & $-24.3 \pm 57.07$ & 0.001 \\
\hline PDW & $18.4 \pm 1.38$ & $17.9 \pm 1.23$ & $0.18 \pm 1.16$ & $>0.05$ \\
\hline MPV (fL) & $8.36 \pm 1.71$ & $8.30 \pm 1.84$ & $0.06 \pm 1.43$ & $>0.05$ \\
\hline Hemoglobin (g/dL) & $13.1 \pm 2.26$ & $13.2 \pm 1.93$ & $-0.07 \pm 2.32$ & $>0.05$ \\
\hline РСТ (ng/mL) & $0.23 \pm 0.07$ & $0.85 \pm 3.30$ & $-0.62 \pm 3.30$ & $>0.05$ \\
\hline Ferritin (ng/mL) & $81.6 \pm 79.97$ & $43.9 \pm 46.32$ & $37.7 \pm 51.26$ & 0.005 \\
\hline CRP (mg/dL) & $2.55 \pm 2.31$ & $0.95 \pm 1.32$ & $1.61 \pm 3.44$ & $>0.05$ \\
\hline $\mathrm{B}_{12}$ vitamini $(\mathrm{pg} / \mathrm{mL})$ & $285.3 \pm 148.02$ & $254.6 \pm 98.73$ & $30.7 \pm 158.4$ & $>0.05$ \\
\hline $\mathrm{D}$ vitamini (ng/mL) & $12.8 \pm 4.77$ & $21.1 \pm 8.08$ & $-8.20 \pm 9.50$ & 0.007 \\
\hline
\end{tabular}

CRP: C-reaktif protein, HbA1C: Hemoglobin A1C, HDL: Yüksek dansiteli lipoprotein, MPV: Ortalama trombosit hacmi, PCT: Trombositler tarafindan kanda kaplanan hacmin yüzdesi, PDW: Trombosit dağılım genişliği , BKİ: Beden kütle indeksi 
Hastaların ALT, AST, GGT değerlerinde cerrahi sonrası anlamlı bir düşüş saptanırken, ALP değerinde fark gözlenmemiştir. GPR, MHR, NLR değerlerinde istatistiksel olarak anlamlı düşüş bulunurken $(\mathrm{p}<0.001)$, PLR değeri açısından fark saptanmamıştır (p>0.05) (Tablo 3).

Tablo 3. Hastaların ameliyat öncesi ve ameliyat sonrası 12. ayda karaciğer enzimleri ve NAYK ile ilgili hesaplanmış parametreler $(n=70)$

\begin{tabular}{|c|c|c|c|c|}
\hline \multirow[t]{2}{*}{ Parametreler } & Ameliyat öncesi & $\begin{array}{c}\text { Ameliyat sonrası } \\
\text { (12. ay) }\end{array}$ & $\begin{array}{l}\text { Eşleştirilmiş } \\
\text { farklılıklar }\end{array}$ & \multirow[t]{2}{*}{$\mathbf{p}$} \\
\hline & $(\overline{\mathrm{X}} \pm \mathrm{S})$ & $(\overline{\mathrm{X}} \pm \mathrm{S})$ & $(\overline{\mathrm{X}} \pm \mathrm{S})$ & \\
\hline ALT (U/L) & $30.7 \pm 16.60$ & $14.7 \pm 6.82$ & $15.96 \pm 15.21$ & $<0.001$ \\
\hline AST (U/L) & $27.1 \pm 15.59$ & $15.1 \pm 5.49$ & $12.0 \pm 15.25$ & $<0.001$ \\
\hline GGT (U/L) & $37.7 \pm 29.76$ & $17.3 \pm 11.03$ & $20.3 \pm 24.15$ & $<0.001$ \\
\hline ALP (U/L) & $71.4 \pm 22.06$ & $65.7 \pm 16.92$ & $5.77 \pm 19.36$ & $>0.05$ \\
\hline GPR & $0.38 \pm 0.33$ & $0.16 \pm 0.12$ & $0.22 \pm 0.25$ & $<0.001$ \\
\hline MHR & $15.1 \pm 3.97$ & $9.11 \pm 2.29$ & $5.99 \pm 4.15$ & $<0.001$ \\
\hline NLR & $2.48 \pm 1.62$ & $1.82 \pm 0.76$ & $0.67 \pm 1.42$ & $<0.001$ \\
\hline PLR & $121.9 \pm 71.58$ & $127.0 \pm 50.33$ & $-5.10 \pm 47.16$ & $>0.05$ \\
\hline
\end{tabular}

ALP: Alkalen fosfataz, ALT: Alanin aminotransferaz, AST: Aspartat aminotransferaz, GGT: Gamaglutamiltransferaz, GPR: GGT-platelet orani, MHR: Mutlak monosit sayısı/HDL oranı, NAYK: Non-alkolik yağlı karaciğer, NLR: Mutlak nötrofil sayısı/mutlak lenfosit sayısı, PLR: Mutlak platelet sayıs/mutlak lenfosit sayısı

Korelasyon analizlerine bakıldığında, ağırlık ile cerrahi sonrası PLR arasında negatif korelasyon, HbA1C (\%) ile cerrahi sonrası PLR arasında negatif korelasyon, HOMA-IR değeri ile cerrahi öncesi ve sonrası GPR arasında pozitif korelasyon, ALT değeri ile cerrahi öncesi ve sonrası GPR arasında pozitif korelasyon, AST değeri ile cerrahi öncesi ve sonrası GPR arasında pozitif korelasyon, AST değeri ile cerrahi öncesi NLR ve PLR arasinda pozitif korelasyon, GGT değeri ile cerrahi öncesi ve cerrahi sonrası GPR arasında pozitif korelasyon, GGT değeri ile cerrahi öncesi MHR değeri arasında pozitif korelasyon, ALP değeri ile cerrahi sonrası MHR arasında pozitif korelasyon, total kolesterol değeri ile cerrahi sonrası NLR arasında pozitif korelasyon, HDL değeri ile cerrahi öncesi ve sonrası MHR değeri arasında negatif korelasyon, TG değeri ile cerrahi öncesi ve sonrası GPR arasında pozitif korelasyon saptanmıştır. GPR ile cerrahi öncesi MHR arasında pozitif korelasyon, cerrahi öncesi ve sonrası PLR arasinda negatif korelasyon saptanmıştır. NLR ile PLR arasında pozitif korelasyon saptanmıştır. TWL \%, EWL \% ile GPR, MHR, PLR, NLR arasında korelasyon saptanmamıştır (Tablo 4).

\section{TARTIŞMA}

$\mathrm{Bu}$ çalışmada, sleeve gastrektomi ameliyatı yapılan hastaların birinci yıl izlemlerinde BKİlerinde anlamlı düşüşün yanı sıra karaciğer fonksiyon testlerinde, total kolesterol, TG, HbA1C (\%) değerinde, HOMA-IR skorunda da anlamlı düşüş, HDL değerinde anlamlı yükselme saptanmıştır. Karaciğer fibrozisi için son ylllarda kullanılmaya başlanan non-invaziv bir test olan GPR değeri ile hem karaciğer fibrozisi hem de inflamasyon değerlendirilmesinde kullanılan NLR değerinde anlamlı düşüş belirlenmiştir. Yine son ylllarda inflamasyon değerlendirilmesinde kullanılan MHR değerinde de anlamlı düşüşün olduğu saptanmıştır. PLR değerinde de istatistiksel olarak anlamlı olmasa da bir düşüş bulunmuştur.

Prospektif çalışmalar, obezitenin metabolik sendromun bir parçası olan İD ile ilişkili olduğunu ortaya koymuştur (6). Obezitede görülen kronik subklinik inflamatuvar durum İ'nin nedeni olabilir. Adipoz dokudaki artış, adipozit hipertrofisi, makrofaj infiltrasyonuna, anjiogenezise, immün sistemin aktivasyonuna ve tümör nekrozis faktör (TNF), interlökin-6 (IL-6), interlökin-1 (IL-1) gibi 
proinflamatuvar sitokinlerin artışına yol açmaktadır (17). Sedimentasyon ve CRP aynı zamanda enfeksiyonların akut döneminde de artış gösterdiği için inflamasyonu göstermede nonspesifiktir (18). Son ylllarda tam kan ve biyokimya parametreleri ile yapılan çalışmalarda NLR, PLR, MHR ile inflamasyon arasında ilişki saptanmıştır $(19,20)$. Yine NLR ile PLR’nin karaciğer fibrozisini predikte edebileceğini gösteren çalışmalar mevcuttur (12,21). Bu araştırmada da ameliyat öncesi ve ameliyat sonrası NLR düzeyleri arasında anlamlı fark mevcuttur.

Tablo 4. Ameliyat öncesi ve ameliyat sonrası antropometrik ölçümler, karaciğer enzimleri ve NAYK ile ilgili bazı parametreler arasındaki korelasyon verileri $(\mathrm{n}=70)$

\begin{tabular}{|c|c|c|c|c|c|c|c|c|}
\hline \multirow[b]{2}{*}{ Parametreler } & \multicolumn{2}{|c|}{ GPR } & \multicolumn{2}{|c|}{ MHR } & \multicolumn{2}{|c|}{ NLR } & \multicolumn{2}{|c|}{ PLR } \\
\hline & $\begin{array}{c}\text { Ameliyat } \\
\text { öncesi }\end{array}$ & $\begin{array}{c}\text { Ameliyat } \\
\text { sonrası }\end{array}$ & $\begin{array}{c}\text { Ameliyat } \\
\text { öncesi }\end{array}$ & $\begin{array}{c}\text { Ameliyat } \\
\text { sonrası }\end{array}$ & $\begin{array}{c}\text { Ameliyat } \\
\text { öncesi }\end{array}$ & $\begin{array}{c}\text { Ameliyat } \\
\text { sonrası }\end{array}$ & $\begin{array}{c}\text { Ameliyat } \\
\text { öncesi }\end{array}$ & $\begin{array}{c}\text { Ameliyat } \\
\text { sonrası }\end{array}$ \\
\hline \multirow[t]{2}{*}{ Ağırlık (kg) } & $\mathrm{r}=0.137$ & $\mathrm{r}=0.213$ & $\mathrm{r}=0.162$ & $\mathrm{r}=0.048$ & $\mathrm{r}=-0.199$ & $\mathrm{r}=-0.220$ & $\mathrm{r}=-0.124$ & $\mathrm{r}=-0.236$ \\
\hline & $\mathrm{p}>0.05$ & $\mathrm{p}>0.05$ & $\mathrm{p}>0.05$ & $\mathrm{p}>0.05$ & $\mathrm{p}>0.05$ & $\mathrm{p}>0.05$ & $\mathrm{p}>0.05$ & $\mathrm{p}=0.049$ \\
\hline \multirow[t]{2}{*}{ BKİ $\left(\mathrm{kg} / \mathrm{m}^{2}\right)$} & $\mathrm{r}=-0.078$ & $\mathrm{r}=-0.012$ & $\mathrm{r}=-0.078$ & $\mathrm{r}=-0.070$ & $\mathrm{r}=-0.051$ & $\mathrm{r}=-0.175$ & $\mathrm{r}=0.019$ & $\mathrm{r}=-0.054$ \\
\hline & $\mathrm{p}>0.05$ & $\mathrm{p}>0.05$ & $p>0.05$ & $p>0.05$ & $\mathrm{p}>0.05$ & $\mathrm{p}>0.05$ & $\mathrm{p}>0.05$ & $\mathrm{p}>0.05$ \\
\hline \multirow[t]{2}{*}{ HbA1C (\%) } & $\mathrm{r}=0.166$ & $\mathrm{r}=0.132$ & $\mathrm{r}=-0.028$ & $\mathrm{r}=-0.049$ & $\mathrm{r}=0.019$ & $\mathrm{r}=-0.012$ & $\mathrm{r}=-0.158$ & $\mathrm{r}=-0.254$ \\
\hline & $p>0.05$ & $p>0.05$ & $\mathrm{p}>0.05$ & $\mathrm{p}>0.05$ & $p>0.05$ & $p>0.05$ & $p>0.05$ & $\mathrm{p}=0.036$ \\
\hline \multirow[t]{2}{*}{ HOMA-IR } & $r=0.299$ & $\mathrm{r}=0.331$ & $\mathrm{r}=-0.057$ & $\mathrm{r}=0.218$ & $\mathrm{r}=0.058$ & $\mathrm{r}=0.152$ & $\mathrm{r}=-0.154$ & $\mathrm{r}=-0.083$ \\
\hline & $\mathrm{p}=0.012$ & $\mathrm{p}=0.005$ & $p>0.05$ & $p>0.05$ & $p>0.05$ & $\mathrm{p}>0.05$ & $p>0.05$ & $p>0.05$ \\
\hline \multirow[t]{2}{*}{$\operatorname{ALT}(\mathrm{U} / \mathrm{L})$} & $\mathrm{r}=0.363$ & $r=0.496$ & $\mathrm{r}=0.131$ & $\mathrm{r}=0.008$ & $\mathrm{r}=0.224$ & $r=0.006$ & $\mathrm{r}=0.198$ & $\mathrm{r}=-0.119$ \\
\hline & $\mathrm{p}=0.002$ & $\mathrm{p}<0.001$ & $\mathrm{p}>0.05$ & $p>0.05$ & $\mathrm{p}>0.05$ & $p>0.05$ & $\mathrm{p}>0.05$ & $p>0.05$ \\
\hline \multirow[t]{2}{*}{ AST (U/L) } & $\mathrm{r}=0.235$ & $\mathrm{r}=0.261$ & $\mathrm{r}=0.116$ & $\mathrm{r}=0.090$ & $\mathrm{r}=0.271$ & $\mathrm{r}=-0.140$ & $\mathrm{r}=0.522$ & $\mathrm{r}=-0.027$ \\
\hline & $\mathrm{p}=0.049$ & $\mathrm{p}=0.044$ & $\mathrm{p}>0.05$ & $\mathrm{p}>0.05$ & $p=0.023$ & $\mathrm{p}>0.05$ & $\mathrm{p}<0.001$ & $\mathrm{p}>0.05$ \\
\hline \multirow[t]{2}{*}{ GGT (U/L) } & $\mathrm{r}=0.941$ & $\mathrm{r}=0.908$ & $\mathrm{r}=0.468$ & $\mathrm{r}=-0.169$ & $\mathrm{r}=-0.014$ & $\mathrm{r}=-0.033$ & $\mathrm{r}=-0.198$ & $\mathrm{r}=0.005$ \\
\hline & $\mathrm{p}<0.001$ & $\mathrm{p}<0.001$ & $\mathrm{p}<0.001$ & $p>0.05$ & $p>0.05$ & $\mathrm{p}>0.05$ & $\mathrm{p}>0.05$ & $p>0.05$ \\
\hline \multirow[t]{2}{*}{$\operatorname{ALP}(\mathrm{U} / \mathrm{L})$} & $\mathrm{r}=0.033$ & $\mathrm{r}=0.182$ & $\mathrm{r}=0.167$ & $r=-0.418$ & $\mathrm{r}=-0.171$ & $\mathrm{r}=-0.189$ & $\mathrm{r}=-0.228$ & $\mathrm{r}=-0.374$ \\
\hline & $\mathrm{p}>0.05$ & $\mathrm{p}>0.05$ & $\mathrm{p}>0.05$ & $\mathrm{p}=0.048$ & $\mathrm{p}>0.05$ & $\mathrm{p}>0.05$ & $\mathrm{p}>0.05$ & $\mathrm{p}>0.05$ \\
\hline \multirow[t]{2}{*}{ Total kolesterol (mg/dL) } & $\mathrm{r}=0.178$ & $\mathrm{r}=0.132$ & $\mathrm{r}=-0.093$ & $\mathrm{r}=-0.343$ & $\mathrm{r}=-0.051$ & $\mathrm{r}=-0.471$ & $r=0.009$ & $\mathrm{r}=-0.313$ \\
\hline & $\mathrm{p}>0.05$ & $\mathrm{p}>0.05$ & $\mathrm{p}>0.05$ & $\mathrm{p}>0.05$ & $\mathrm{p}>0.05$ & $\mathrm{p}=0.042$ & $p>0.05$ & $\mathrm{p}>0.05$ \\
\hline \multirow[t]{2}{*}{ HDL (mg/dL) } & $\mathrm{r}=-0.160$ & $\mathrm{r}=0.155$ & $\mathrm{r}=-0.292$ & $\mathrm{r}=-0.412$ & $\mathrm{r}=0.207$ & $\mathrm{r}=0.023$ & $\mathrm{r}=0.102$ & $\mathrm{r}=0.163$ \\
\hline & $\mathrm{p}>0.05$ & $p>0.05$ & $\mathrm{p}=0.014$ & $\mathrm{p}<0.001$ & $p>0.05$ & $p>0.05$ & $p>0.05$ & $p>0.05$ \\
\hline \multirow[t]{2}{*}{ Trigliserit (mg/dL) } & $\mathrm{r}=0.441$ & $\mathrm{r}=0.424$ & $\mathrm{r}=0.093$ & $\mathrm{r}=-0.160$ & $\mathrm{r}=-0.143$ & $\mathrm{r}=0.081$ & $\mathrm{r}=-0.129$ & $\mathrm{r}=-0.223$ \\
\hline & $\mathrm{p}=0.005$ & $\mathrm{p}=0.049$ & $p>0.05$ & $p>0.05$ & $p>0.05$ & $p>0.05$ & $p>0.05$ & $p>0.05$ \\
\hline \multirow[t]{2}{*}{ TWL } & - & $\mathrm{r}=-0.038$ & - & $\mathrm{r}=0.199$ & - & $\mathrm{r}=-0.117$ & - & $\mathrm{r}=-0.061$ \\
\hline & & $\mathrm{p}>0.05$ & & $p>0.05$ & & $\mathrm{p}>0.05$ & & $\mathrm{p}>0.05$ \\
\hline \multirow[t]{2}{*}{ EWL } & - & $r=-0.107$ & - & $\mathrm{r}=0.125$ & - & $\mathrm{r}=0.185$ & - & $\mathrm{r}=0.170$ \\
\hline & & $p>0.05$ & & $p>0.05$ & & $p>0.05$ & & $p>0.05$ \\
\hline \multirow[t]{2}{*}{ GPR } & - & - & $\mathrm{r}=0.423$ & $\mathrm{r}=-0.175$ & $\mathrm{r}=0.041$ & $\mathrm{r}=-0.141$ & $\mathrm{r}=-0.269$ & $\mathrm{r}=-0.239$ \\
\hline & & & $\mathrm{p}<0.001$ & $p>0.05$ & $p>0.05$ & $p>0.05$ & $\mathrm{p}=0.024$ & $\mathrm{p}=0.046$ \\
\hline \multirow[t]{2}{*}{ MHR } & $\mathrm{r}=0.423$ & $r=-0.175$ & - & - & $\mathrm{r}=-0.100$ & $\mathrm{r}=0.131$ & $\mathrm{r}=-0.111$ & $\mathrm{r}=-0.057$ \\
\hline & $\mathrm{p}<0.001$ & $\mathrm{p}>0.05$ & & & $\mathrm{p}>0.05$ & $\mathrm{p}>0.05$ & $\mathrm{p}>0.05$ & $\mathrm{p}>0.05$ \\
\hline \multirow[t]{2}{*}{ NLR } & $\mathrm{r}=0.041$ & $\mathrm{r}=-0.141$ & $\mathrm{r}=-0.100$ & $\mathrm{r}=0.131$ & - & - & $\mathrm{r}=0.564$ & $\mathrm{r}=0.592$ \\
\hline & $p>0.05$ & $p>0.05$ & $p>0.05$ & $\mathrm{p}>0.05$ & & & $\mathrm{p}<0.001$ & $\mathrm{p}<0.001$ \\
\hline \multirow[t]{2}{*}{ PLR } & $\mathrm{r}=-0.269$ & $\mathrm{r}=-0.239$ & $\mathrm{r}=-0.111$ & $r=-0.057$ & $\mathrm{r}=0.564$ & $\mathrm{r}=0.592$ & - & - \\
\hline & $\mathrm{p}=0.024$ & $\mathrm{p}=0.046$ & $\mathrm{p}>0.05$ & $\mathrm{p}>0.05$ & $\mathrm{p}<0.001$ & $\mathrm{p}<0.001$ & & \\
\hline
\end{tabular}

ALP: Alkalen fosfataz, ALT: Alanin aminotransferaz, AST: Aspartat aminotransferaz, EWL: Aşırl ağtrlık kaybı, GGT: Gamaglutamiltransferaz, GPR: GGT-platelet oranı, HbA1C: Hemoglobin A1C, HDL: Yüksek dansiteli lipoprotein, MHR: Mutlak monosit sayısı/HDL oranı, NAYK: Non-alkolik yağlı karaciğer, NLR: Mutlak nötrofil sayısı/mutlak lenfosit sayısı, PLR: Mutlak platelet sayısı/mutlak lenfosit sayısı, TWL: Toplam ağırlık kaybı, BKİ: Beden kütle indeksi 
Obezitenin artışı ile birlikte NAYK sıklığı giderek artmaktadır. NAYK'ın metabolik sendromun bir parçası olduğuna ve İD’nin bu patolojiyi başlatan olay olduğuna dair uluslararası bir konsensus vardır. NAYK, karaciğerde basit bir yağlanmadan, steatohepatite, siroza, hepatoselüler kansere ve nihayetinde karaciğer yetmezliğine yol açabilen geniş bir spektrum hastalığı kapsamaktadır. Ağırlık kaybı obez NAYK'lı hastalardaki temel tedavidir (22). Karaciğer biyopsisi karaciğerdeki hasarı göstermede altın standart olmasına rağmen komplikasyonları nedeni ile hasta takibinde kullanmada invaziv bir yöntemdir. Son ylllarda APRI, FIB-4 gibi noninvaziv testlere ek olarak hesaplaması çok daha kolay GPR değerinin karaciğer fibrozis derecesini göstermede etkili olduğu saptanmıştır $(10,11)$. Uslu ve arkadaşları (15), MHR oranının metabolik sendromlu hastalarda kontrol grubundan daha yüksek olduğunu aynı zamanda hastalık şiddeti ile pozitif korelasyon gösterdiğini belirtmişlerdir. Bu araştırmada da GPR ve MHR düzeyleri açısından ameliyat öncesi ve ameliyat sonrası değerler arasında anlamlı farklılık saptanmıştır.

Metabolik sendromu değerlendirmede HOMAIR, ALT, AST, GGT ve TG klinik pratikte kullanılan parametrelerdir. $\mathrm{Bu}$ parametreler ile GPR arasinda pozitif korelasyon saptanması, sleeve gastrektomi olmuş obez hastaların takibinde kullanılabileceğini düşündürmektedir.

$\mathrm{Bu}$ araştırmanın en önemli kısıtlılığı retrospektif dizaynı, hasta sayısının azlığı ve izlem süresinin kısalığıdır. Bu konuda yapılacak daha çok hasta katılımlı, daha uzun izlem süresi olan prospektif çalışmalara gereksinme vardır. GPR, MHR ve NLR sleeve gastrektomi olan NAYKH'ın eşlik ettiği morbid obez hastaların takibinde kullanılabilecek noninvaziv ve kolay ulaşılabilir, ucuz parametrelerdir.

Çıkar çatışması - Conflict of interest: Yazarlar çıkar çatışması olmadığını beyan ederler. - The authors declare that they have no conflict of interest.

\section{KAYNAKLAR}

1. World Health Organization (WHO). Obesity and Overweight. Available at: http://www.who.int/topics/ obesity/en/ Accessed September 14, 2018.

2. Huang Z, Willett WC, Manson JE, Rosner B, Stampfer MJ, Speizer FE et al. Body weight, weight change, and risk for hypertension in women. Ann Intern Med 1998;128(2):81-8.

3. Buchwald H, Avidor Y, Braunwald E, Jensen MD, Pories W, Fahrbach K, et al. Bariatric surgery: a systematic review and meta-analysis. JAMA 2004;292:1724-37.

4. Day CP. Non-alcoholic fatty liver disease: current concepts and management strategies. Clin Med 2006;6(1):19-25.

5. Bellentani S, Marino M. Epidemiology and natural history of non-alcoholic fatty liver disease (NAFLD). Ann Hepatol 2009;8(Suppl 1):4-8.

6. Zhang C, Zhang J, Liu Z, Zhou Z. More than an antidiabetic bariatric surgery, metabolic surgery alleviates systemic and local inflammation in obesity. Obes Surg 2018;28(11):3658-68.

7. Clark JM, Alkhuraishi AR, Solga SF, Alli P, Diehl AM, Magnuson TH. Roux-en-Y gastric bypass improves liver histology in patients with non-alcoholic fatty liver disease. Obes Res 2005;13:1180-6.

8. Johansson HE, Haenni A, Zethelius B. Platelet counts and liver enzymes after bariatric surgery. J Obes 2013;567984.

9. Randell EW, Twells LK, Gregory DM, Lester KK, Daneshtalab N, Dillon C, et al. Preoperative and postoperative changes in CRP and other biomarkers sensitive to inflammatory status in patients with severe obesity undergoing laparoscopic sleeve gastrectomy. Clin Biochem 2018;52:13-9.

10. Enomoto H, Bando Y, Nakamura H, Nishiguchi S, Koga M. Liver fibrosis markers of nonalcoholic steatohepatitis. World J Gastroenterol 2015;21(24):7427-35.

11. Wang RQ, Zhang QS, Zhao SX, Niu XM, Du JH, Du HJ Nan YM. Gamma glutamyl transpeptidase to platelet ratio index is a good noninvasive biomarker for predicting liver fibrosis in Chinese chronic hepatitis B patients. J Int Med Res 2016;44(6):1302-13.

12. Alkhouri N, Morris-Stiff G, Campbell C, Lopez R, Tamimi TA, Yerian L, et al. Neutrophil to lymphocyte ratio: a new marker for predicting steatohepatitis and fibrosis in patients with nonalcoholic fatty liver disease. Liver Int 2012;32(2):297-302.

13. Akboga MK, Canpolat U, Yuksel M, Yayla C, Yilmaz S, 
Turak O, et al. Platelet to lymphocyte ratio as a novel indicator of inflammation is correlated with the severity of metabolic syndrome: A single center large-scale study. Platelets 2016;27(2):178-83.

14. Buyukkaya E, Karakas MF, Karakas E, Akçay AB, Tanboga IH, Kurt M, et al. Correlation of neutrophil to lymphocyte ratio with the presence and severity of metabolic syndrome. Clin Appl Thromb Hemost 2014;20(2):159-63.

15. Uslu AU, Sekin Y, Tarhan G, Canakcı N, Gunduz M, Karagulle M. Evaluation of monocyte to high-density lipoprotein cholesterol ratio in the presence and severity of metabolic syndrome. Clin Appl Thromb Hemost 2018;24(5):828-33.

16. Hatoum IJ, Kaplan LM. Advantages of Percent weight loss as a method of reporting weight loss after Roux-en-Y Gastric Bypass. Obesity (Silver Spring) 2013;21(8):151925.

17. Dowman JK, Tomlinson JW, Newsome PN. Pathogenesis of non-alcoholic fatty liver disease. QJM 2010;103(2):71-
83.

18. Bray C, Bell LN, Liang H, Haykal R, Kaiksow F, Mazza JJ, et al. Erythrocyte sedimentation rate and C-reactive protein measurements and their relevance in clinical medicine. WMJ 2016;115(6):317-21.

19. Fest J, Ruiter R, Ikram MA, Voortman T, van Eijck CHJ, Stricker BH. Reference values for white blood-cellbased inflammatory markers in the Rotterdam Study: a population-based prospective cohort study. Sci Rep 2018;8(1):10566.

20. Yılmaz M, Kayançiçek H. A new inflammatory marker: elevated monocyte to HDL cholesterol ratio associated with smoking. J Clin Med 2018;7(4):76.

21. Alsebaey A, Elhelbawy M, Waked I. Platelets-tolymphocyte ratio is a good predictor of liver fibrosis and insulin resistance in hepatitis $C$ virus-related liver disease. Eur J Gastroenterol Hepatol 2018;30(2):207-11.

22. Cazzo E, Pareja JC, Chaim EA. Nonalcoholic fatty liver disease and bariatric surgery: a comprehensive review. Sao Paulo Med J 2017;135(3):277-95. 